\title{
One-step synthesis of spontaneously graphitized nanocarbon using cobalt-nanoparticles
}

\author{
Sahar Elnobi ${ }^{1,2}$ (1) - Subash Sharma ${ }^{1}$. Tetsuya Ohsugi ${ }^{1}$ - Balaram Paudel ${ }^{1}$. Golap Kalita ${ }^{1}$. Mohd Zamri Mohd Yusop ${ }^{3}$. \\ Muhammed Emre Ayhan ${ }^{4}$. Zhen Quan Cavin $\mathrm{Ng}^{5}$. Daniel H. C. Chua ${ }^{5} \cdot$ Masaki Tanemura $^{1}$
}

Received: 8 September 2020 / Accepted: 20 November 2020 / Published online: 4 December 2020

(c) Springer Nature Switzerland AG 2020

\begin{abstract}
Amorphous carbon (a-C) films containing metallic Cobalt nanoparticles (Co NPs) were deposited onto microgrids and $\mathrm{SiO}_{2} / \mathrm{Si}$ substrates by a magnetron sputter-deposition technique at room temperature (RT) using aC target with an attachment of a small Co platelet. Transmission electron microscopy (TEM) with a fast Fourier-transform (FFT) revealed the short-range ordering of the lattice corresponding to graphite (002) between Co NPs in the amorphous $\mathrm{C}$ matrix. The 2D peak and graphite (002) peak were clearly observed in Raman spectra and x-ray diffraction (XRD), respectively, for the Co-C films. X-ray photoelectron spectroscopy analyses were used to determine the metallic state of Co NPs and $\mathrm{sp}^{2}$ graphitization in the film. Thus, the Co NPs exhibited higher catalytic activity in spontaneous graphitization at lowtemperature than Ni-NPs prepared under the same conditions. So, the metallic NPs were concluded to be promising as the catalyst for the ultra-low temperature graphitization in the solid-phase reaction.
\end{abstract}

Keywords Room temperature synthesis · Spontaneous graphitization · Co-nanoparticle · Magnetron sputtering

\section{Introduction}

Graphene is a two-dimensional (2D) monolayer of $\mathrm{sp}^{2}$-hybridized carbon atoms arranged in a honeycomb lattice. Graphene has potential applications owing to its unique incomparable electronic properties, high thermal conductivity and excellent mechanical properties [1-4]. Various techniques have been utilized to fabricate 2D materials such as graphite exfoliation, chemical vapor deposition (CVD) and solid-phase reaction. In the solidphase reaction method, the solid carbon source, such as a polymer film or an amorphous carbon (a-C) film, is annealed on a metal catalyst substrate, e.g., nickel (Ni) and cobalt (Co) [5-11].
In the graphene research, one of the big issues is its low-temperature growth. To achieve this, several novel catalysts have been suggested. In our previous papers also, we have demonstrated the graphene formation on $\mathrm{SiO}_{2}$ substrates by vacuum annealing at 150 and $250^{\circ} \mathrm{C}$ for the stacked amorphous carbon and catalyst films of low melting point, such as indium (In) and tin (Sn), respectively $[12,13]$. Abd Elhamid et al. have synthesized graphene at room temperature (RT) using pulsed laser deposition (PLD) of highly oriented pyrolytic graphite target on complex $\mathrm{Ni}$-Cu substrates [14]. Recently, Nakajima et al. have demonstrated the formation of multilayer graphene (MLG) films directly on $\mathrm{SiO}_{2}$ glass substrate using amorphous carbon at a temperature as low as $400{ }^{\circ} \mathrm{C}$ by a simple

$\triangle$ Sahar Elnobi, sahar.elnobi@sci.svu.edu.eg; $\bowtie$ Masaki Tanemura, tanemura.masaki@nitech.ac.jp| ${ }^{1}$ Department of Physical Science and Engineering, Graduate School of Engineering, Nagoya Institute of Technology, Gokiso-cho, Showa-ku, Nagoya 466-8555, Japan. ${ }^{2}$ Department of Physics, Faculty of Science, South Valley University, Qena 83523, Egypt. ${ }^{3}$ Department of Materials, Faculty of Mechanical Engineering, Universiti Teknologi Malaysia, 81310 Skudai, Johor, Malaysia. ${ }^{4}$ Department of Metallurgical and Materials Engineering, Faculty of Engineering and Architecture, Necmettin Erbakan University, Konya, Turkey. ${ }^{5}$ Department of Materials Science and Engineering, National University of Singapore, 9 Engineering Drive 1, Singapore, Singapore. 
sputtering technique using Co catalysts with high carbon solid solubility [15].

Recently, Asaka et al. have demonstrated the spontaneous local graphitization at RT for an amorphous carbon film deposited onto $\mathrm{NaCl}$ substrates with a pre-deposition of Ni NPs [16]. In our previous paper also, we have demonstrated the local graphitization of amorphous carbon films containing Ni NPs which were deposited on insulator substrates by a simple one-step magnetron sputtering of a C-Ni target at RT [17]. So, the catalyst in NP form must be promising for the low-temperature graphitization in the solid-phase reaction. Co is a well-known catalyst for graphene growth and possesses a higher $C$ solubility than $\mathrm{Ni}$ [18]. Thus, the similar catalytic ability in the low-temperature graphitization may be expected for Co NPs [19-21]. In addition, $\mathrm{C}$ film containing $\mathrm{Co} \mathrm{NPs}$ (referred to a $\mathrm{Co}-\mathrm{C}$ film hereafter) attracts the great interest for various applications such as magnetic data storage and magnetic resonance imaging [22]. In what follows, we will deal with the spontaneous graphitization at RT by simple one-step syntheses of Co-C films for the first time, leading to a strategy to achieve the ultra-low temperature graphene growth.

\section{Experimental method}

The deposition of Co-C films was performed at RT onto commercially available microgrids (NS-M15, Okenshoji) for TEM and $\mathrm{SiO}_{2}$ covered $\mathrm{Si}$ substrates $\left(\mathrm{SiO}_{2} / \mathrm{Si}\right)$ using radiofrequency (RF) magnetron sputtering (SCOTT-C3 (VTR-151 M/SRF), ULVAC KIKO Inc.) under base pressure of $3.0 \times 10^{-4} \mathrm{~Pa}$. Ar plasma was used for the film deposition. The RF power was set to $30 \mathrm{~W}$ and the deposition time was $5 \mathrm{~min}$. For the Co-C film deposition, a carbon (graphite) disk $50 \mathrm{~mm}$ in diameter with an attachment of a small Co platelet (referred to a Co-C target hereafter) was prepared. The thicknesses of the deposited Co-C film were $7 \mathrm{~nm}$.

The prepared films were analyzed by Raman spectroscopy (NRS 3300 laser Raman spectrometer), at laser wavelength $532.08 \mathrm{~nm}$. TEM analyses were performed using a high-resolution TEM, JEM ARM 200F, operating at $200 \mathrm{kV}$, equipped with dispersive $x$-ray spectroscopy (EDS). The crystallographic structure was analyzed by an x-ray diffraction (XRD) system (Rigaku RINT 2100 diffractometer) equipped with a $\mathrm{Cu}$ target. The Ni-filtered $\mathrm{Cu}$ Ka radiation $(\lambda=1.5408 \AA)$ was used. The $X$-ray tube voltage and current were $40 \mathrm{kV}$ and $30 \mathrm{~mA}$, respectively. For the chemical state analysis of the film, XPS measurements were performed using a Kratos Analytical Axis UltraDLD UHV spectrometer with a monochromatized Al.Ka X-ray source (1486.6 eV). The take-off angle was $90^{\circ}$ and the constant analyzer energy mode was employed. The pass energy of the survey scan was $120 \mathrm{eV}$ and the narrow scan was $20 \mathrm{eV}$. In order to obtain the in-depth information of the Co-C films, light sputtering with $\mathrm{Ar}^{+}$ions at $5 \mathrm{kV}$ for $1 \mathrm{~min}$ was done. The ion incidence angle was $60^{\circ}$ normal to the surface. The ion current density and the etching rate were $0.5 \mathrm{~mA} /$ $\mathrm{cm}^{2}$ and $\sim 1 \mathrm{~nm} / \mathrm{min}$, respectively. During the ion etching, the working pressure was kept at $1 \times 10^{-5} \mathrm{~Pa}$, due to the differential pumping. The XPS spectra obtained were deconvolved using curve fitting on an $80 / 20 \%$ Gaussian/ Lorentian peak. All the resolved peaks were used for both qualitative identification and semiquantitative calculations. Regarding the peaks used, the sufficient background was fulfilled for the comparison.

\section{Results and discussion}

Figure 1a shows a typical high-magnification TEM image of a Co-C film deposited onto a microgrid. At a glance, black contrast parts dispersed over the film. As is typically exemplified by rectangular A in Fig. 1a, a careful inspection of some black contrast parts showed the lattice fringes of $0.202 \mathrm{~nm}$ spacing corresponding to Co (002), indicating that the black contrast parts were Co NPs. An inset in Fig. 1a is a further magnified image of the rectangular region $B$ in Fig. $1 a$, disclosing the ordered lattice fringes of the short-range between the black contrast parts. The spacing of the ordered fringes was measured to be $\sim 0.345 \mathrm{~nm}$ which corresponds to the lattice spacing of graphite (002). Such a short-range ordering corresponding to graphite (002) was observed over the film, and some of them were indicated by yellow arrows in Fig. $1 \mathrm{a}$.

Figure $1 \mathrm{~b}$ shows a fast Fourier transform (FFT) image taken from the whole area shown in Fig. 1a. The FFT is composed of spotty rings and a relatively broad ring corresponding to the graphite (002) plane. The relatively broad ring indicates that the crystallite was quite small in size, agreeing well with the observation in Fig. 1a. In Fig. 1b, spotty ring patterns corresponded to Co (002), (101), (102), (103) and $\mathrm{CoO}(002)$ planes. The size distribution of the Co NPs (black contrast parts) in Fig. 1a is shown in Fig. 1c, revealing that the NPs ranged from $\sim 1.8$ to $\sim 2.8 \mathrm{~nm}$ in size with an average size of $\sim 2.1 \mathrm{~nm}$ and the number density of the NPs was $\sim 6.3 \times 10^{4} \mu \mathrm{m}^{-2}$. The $\mathrm{Co} / \mathrm{C}$ concentration ratio was determined to be 2.78/88.85 from EDS analysis, as seen in Fig. $1 \mathrm{~d}$. Agreeing with the FFT in Fig. $1 \mathrm{~b}$, the oxygen peak in the EDS spectrum is approximately as large as the Co peak.

Figure 2 shows the XRD pattern for a Co-C film deposited onto a $\mathrm{SiO}_{2} / \mathrm{Si}$. It can be seen that the as-prepared sample shows a broad diffraction peak at about $2 \theta=20^{\circ}$ (see Fig. 2b) corresponding to graphite (002) plane commonly observed for reduced graphene oxides ( $\mathrm{rGOs}$ ) [23-25]. The broad peak would be due to the localized 

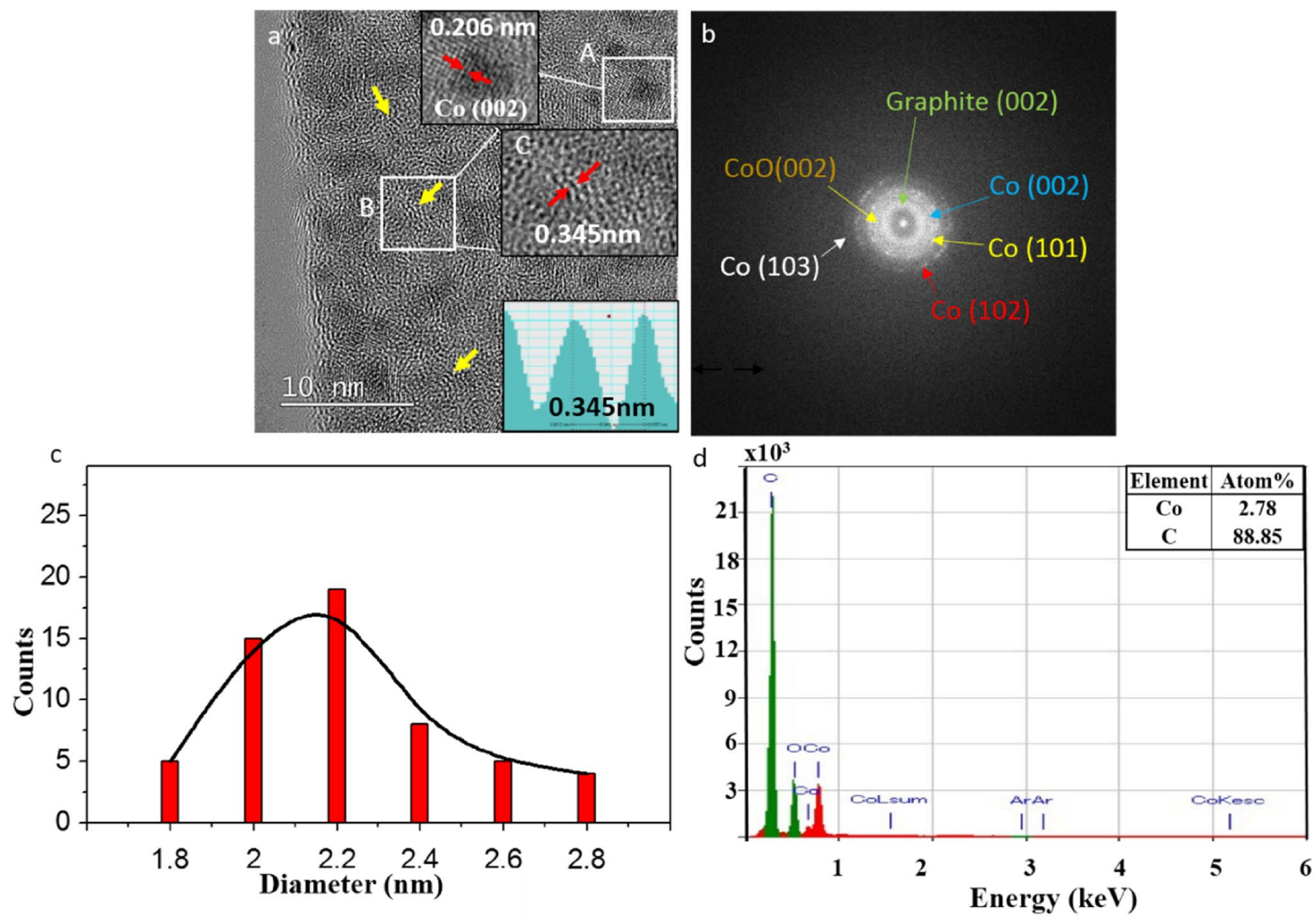

Fig. 1 a TEM image of a Co-C film deposited on a microgrid at RT. The upper inset in a shows an enlarged image of the rectangular region $B$. The lower inset represents an intensity line profile of the arrow-indicated lattice region in the upper inset, indicating the

interlayer spacing of $0.345 \mathrm{~nm}$. b FFT image corresponding to a. c Size distribution of Co.NPs in Fig. 1a, and d EDS spectrum of the $\mathrm{Co}-\mathrm{C}$ film to estimate the Co content

graphitized region and the imperfect crystallinity of the graphitic layers as seen in the TEM image (Fig. 1a). The XRD pattern in Fig. 2 exhibits the peaks indexed as Co (004), $\mathrm{CoO}$ (111), Si (400) and $\mathrm{Co}(110)$ at $2 \theta=33,62,69$ and $75^{\circ}$, respectively.

In order to confirm the graphitization more quantitatively, the film deposited onto a $\mathrm{SiO}_{2} / \mathrm{Si}$ substrate was analyzed by Raman spectroscopy. An optical microscope image is shown in Fig. 3a, disclosing those flake-like regions of dark contrast indicated by arrows located on the flat surface of blue color (background-like region). Figure $3 \mathrm{~b}$ and $\mathrm{c}$ shows Raman spectra obtained at the flake-like region and the surrounding background-like region in Fig. 3a, respectively. As seen in Fig. 3b, the spectra obtained from the flake-like region consists of intense $G$ and $2 D$ peaks centered at 1587 and $2700 \mathrm{~cm}^{-1}$, respectively, with an intense $D$ peak at $1355 \mathrm{~cm}^{-1}$, revealing the formation of multilayer graphene with defects. By contrast, the Raman spectrum of the background-like

region (Fig. 3c) was characterized by $D$ and $G$ peaks at 1390 and $1560 \mathrm{~cm}^{-1}$, respectively. Although the distinct 2D peak was not observable in the Raman spectrum of the background-like region, the Raman spectrum for this region was different from the amorphous carbon film [26]. Also, the spectrum for the background-like region was quite similar to the spectra reported previously for partially graphitized samples $[16,17]$. The intensity ratios of $D$ and $G$ peaks $\left(I_{\mathrm{D}} / I_{\mathrm{G}}\right)$ were calculated to be $\sim 0.79$ and 0.92 for the flake-like and background-like regions, respectively. The difference in Raman spectra for those regions would be explained as follows: Different from the surface of amorphous porous $\mathrm{C}$ microgrid for TEM, the deposited $\mathrm{Co}-\mathrm{C}$ would agglomerate readily relatively in long-range, resulting in the macroscopic flake-like region on the $\mathrm{SiO}_{2}$ surface for Raman analysis. In this macroscopically agglomerated area, namely the flake-like regions, due to the easier movement of atoms, the inclusion of $C$ atoms into clustering $\mathrm{Co}-\mathrm{C}$ and precipitation of graphitic layer 
Fig. 2 XRD spectra for a Co-C film deposited onto a $\mathrm{SiO}_{2} /$ Si. a Wide chart for the overall analysis, and $\mathbf{b}-\mathbf{d}$ narrow charts. The dashed rectangular indicates the broad peak corresponding to the graphite (002) plane
Fig. 3 a optical microscope image of a Co-C film deposited on $\mathrm{SiO}_{2} / \mathrm{Si}$ at RT. $\mathbf{b}$ and $\mathbf{c}$ Typical Raman spectra taken at one of the arrow-indicated flake-like regions of the dark contrast and surrounding backgroundlike region of the blue color in a, respectively
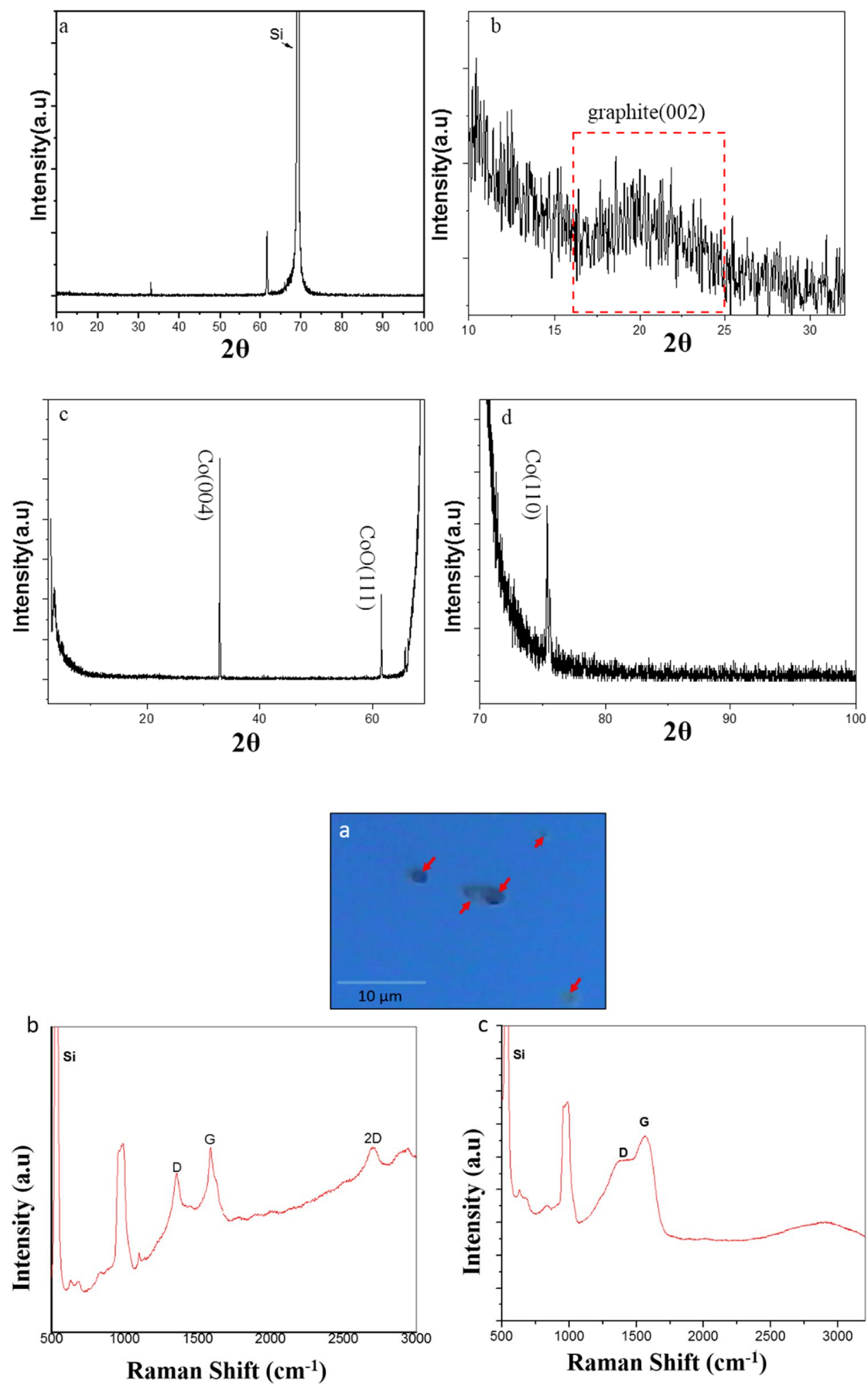

would occur more actively than at the surrounding area. The graphitization mechanism will be discussed later in detail. The present observations suggest that the spontaneous graphitization of a-C catalyzed by Co NPs occurs even at RT, similar to the case of Ni NPs [17].
For the further confirmation of the chemical states of the respective elements, XPS measurement before and after the light sputtering was carried out for a Co-C film deposited on a $\mathrm{SiO}_{2} / \mathrm{Si}$ at RT. Figure 4a shows the survey spectra of the $\mathrm{C}-\mathrm{Co}$ film, revealing that $\mathrm{Co}$ was prominent 

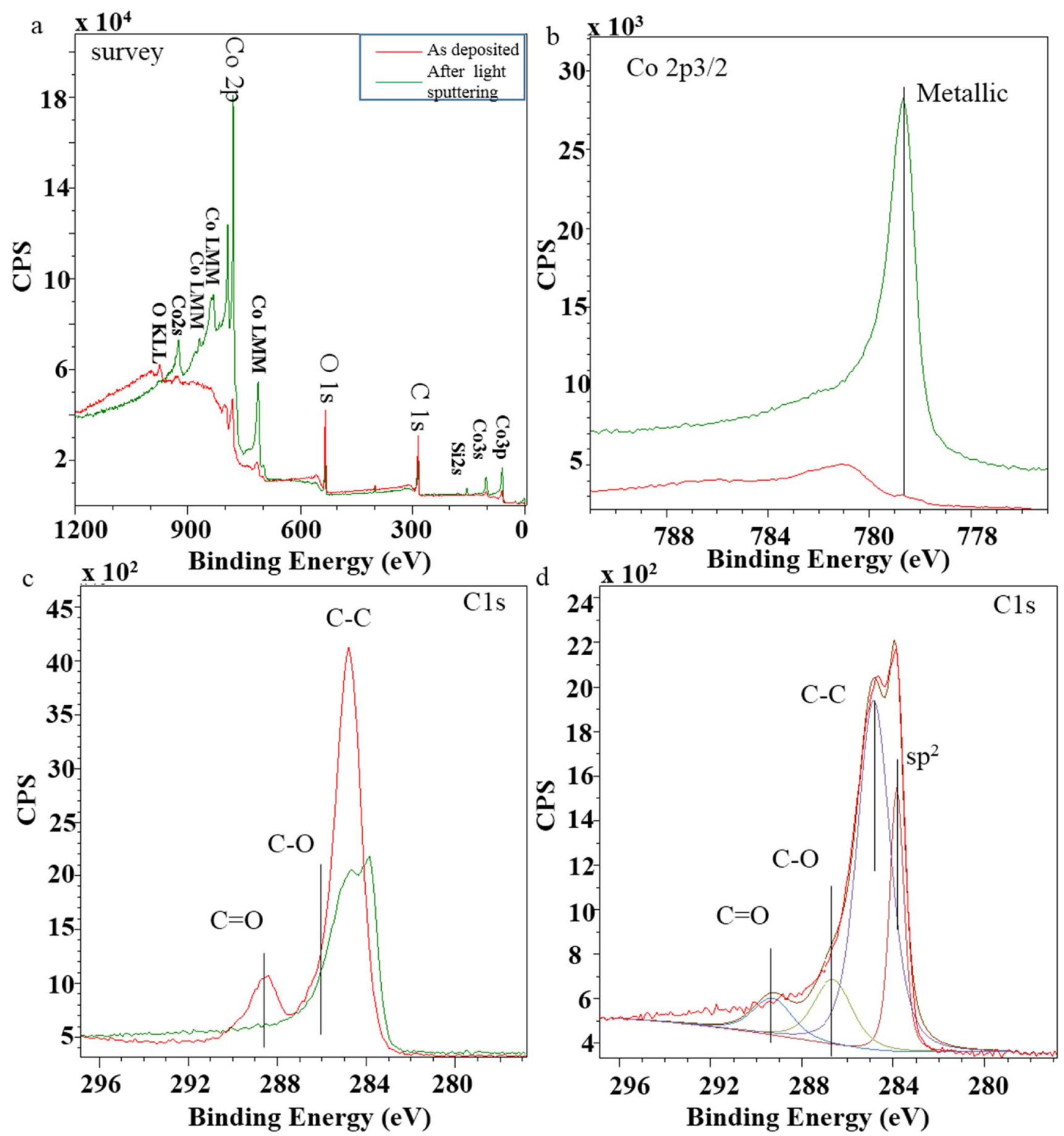

Fig. 4 XPS spectra of a Co-C film deposited on a $\mathrm{SiO}_{2} / \mathrm{Si}$ substrate. a Survey and narrow spectra of $\mathbf{b}$ Co $2 p_{3 / 2}$ and $\mathbf{c} C 1$ s taken before (red line) and after (green line) light sputtering of the film. $\mathbf{d}$ The

after the light sputtering. As is also seen in $\mathrm{Co} 2 \mathrm{p} 3 / 2$ peak, Fig. 4b, the chemical states of Co NPs in the film were different from that at the top surface; metallic Co was preserved in the film even after the exposure to air, whereas the metallic state was not clear at the top surface due to the surface oxidization and contamination. Figure $4 \mathrm{c}$

curve fitting result of the $\mathrm{C} 1 \mathrm{~s}$ peak for the spectrum is taken after light sputtering in c

shows a narrow spectra of the $\mathrm{C} 1 \mathrm{~s}$ peak. The peaks at about 284-285 and $\sim 288.6 \mathrm{eV}$ were assigned to $\mathrm{C}-\mathrm{C}$ and $\mathrm{C}=\mathrm{O}$ components, respectively, and a bump at $\sim 286 \mathrm{eV}$ was attributed to the $\mathrm{C}-\mathrm{O}$ component. For NPs in the film, $\mathrm{C}=\mathrm{O}$ and $\mathrm{C}-\mathrm{O}$ components dramatically reduced and the splitting of $\mathrm{C}-\mathrm{C}$ related peak was observable. For precise 
analysis, deconvolution of the C1s spectrum obtained after light sputtering was carried out as shown in Fig. 4d. Apparently, C-C-related peak consisted of two components peaked at 283.52 and $284.53 \mathrm{eV}$. The former peak position is closed to the reported value for the graphitic $\mathrm{sp}^{2}$ carbon [27], while the latter would be general C-C bonding including the $\mathrm{sp}^{3}$ component [28]. From the XPS analyses, it is concluded that the metallic state of Co NPs was preserved and the graphitization occurred in the film. This agrees well with the TEM observation shown in Fig. 1.

The mechanism of the graphitization of NPs-carbon composite films at RT and the negative effect of the oxide in the graphitization were discussed elsewhere for Ni NPs [17]. In brief, with a decrease in particle size, in general, the melting point decreases while the carbon solubility increases [29-31]. For NPs-carbon composite films, due to the decrease in melting point, the situation of $C$ atoms would be similar to that at high temperatures even at $\mathrm{RT}$, namely $\mathrm{C}$ atoms readily displace to form $\mathrm{sp}^{2}$ bonding $[16,17]$. In the film deposition process, agglomeration of NPs would occur, and the solubility of $C$ would slightly decrease with increasing NP size in the agglomeration process, yielding a graphitized layer behind the trace of moving agglomerated NPs. It is also the case for Co NPs observed here.

It is interesting to compare the catalytic activity of NPs in graphitization at low temperature for $\mathrm{Co}$ with $\mathrm{Ni}$. For the $\mathrm{Ni}$ NP case as was reported previously [17], no distinct 2D peak was detected in the Raman spectrum for the $\mathrm{Ni}-\mathrm{C}$ film deposited on $\mathrm{SiO}_{2} / \mathrm{Si}$ at $\mathrm{RT}$, where the average diameter of the Ni NPs $(\sim 2.1 \mathrm{~nm})$, the atomic concentration ratio of $\mathrm{Ni} / \mathrm{C}$ determined by EDS (2.27/88.18), and the partially oxidized situation of NPs were almost the same as the Co-C film tested here [17]. These facts indicate that the catalytic activity in low-temperature graphitization is higher for $\mathrm{Co}$ than $\mathrm{Ni}$. The heat of oxide formation is almost identical for $\mathrm{Ni}$ and $\mathrm{Co}$ [28], and the melting point is also almost identical for $\mathrm{Ni}(1728 \mathrm{~K})$ and $\mathrm{Co}(1768 \mathrm{~K})$. So, the possible reason for the difference in their catalytic activities in low-temperature graphitization would be the difference in carbon solubility $\left(2.03\right.$ for $\mathrm{Ni}$, and 3.41 for Co at $1000^{\circ} \mathrm{C}$ [18]). At an early stage of the film deposition, clustering of Co atoms would occur and a higher amount of $C$ atoms would be included in clustering $\mathrm{Co}$ than in clustering $\mathrm{Ni}$. Then, with their agglomeration, the $C$ solubility would decrease slightly, resulting in a precipitation of graphitized layer behind the trace of agglomeration. The amount of the precipitation of graphitized layer would depend on the initially involved $C$ content. This would be the reason why $\mathrm{Co}$ is superior to $\mathrm{Ni}$ in the catalytic activity. The precipitation process will be similar to the growth process in the chemical vapor deposition (CVD). In fact, for the CVD growth also, better catalytic activity in graphene growth for Co films than Ni films was observed [21]. We are now planning the systematic investigation on the lower temperature graphitization using NPs for various metals, and the result will be dealt with in a forthcoming paper.

\section{Conclusions}

In summary, we have studied the spontaneous graphitization of as-grown amorphous carbon films containing Co NPs as a catalyst at RT. Local graphitization has been confirmed by high-resolution TEM, XRD, Raman and XPS analyses. Also, it was demonstrated that the metallic Co NPs were preserved even after the air exposure of $\mathrm{Co}-\mathrm{C}$ films. Moreover, Co NPs showed better catalytic properties in the low-temperature graphitization than Ni NPs, likely due to the higher $\mathrm{C}$ solubility than $\mathrm{Ni}$. Based on these findings, it was concluded that the amorphous $C$ films containing Co NPs will be promising for the low-temperature graphitization.

Acknowledgement This work was partially supported by JSPS Grantin-Aid for Scientific Research (B) Grant No. $20 \mathrm{H} 02618$.

\section{Compliance with ethical standards}

Conflict of interest The authors declare that there is no conflict of interest regarding the publication of this article.

\section{References}

1. Geim AK, Novoselov KS (2007) The rise of graphene. Nat Mater 6:183-191

2. Deng J, Zheng R, Zhao Y, Cheng G (2012) Vapor a solid growth of few-layer graphene using radio frequency sputtering deposition and its application on field emission. ACS Nano 6:3727-3733

3. Zhu Y, Murali S, Cai W, Li X, Suk JW, Potts JR, Ruoff RS (2010) Graphene and graphene oxide: Synthesis, properties, and applications. Adv Mater 22:3906-3924

4. Allen MJ, Tung VC, Kaner RB (2010) Honeycomb carbon: a review of graphene. Chem Rev 110:132-145

5. Novoselov KS, Geim AK, Morozov SV, Jiang D (2004) Electric field effect in atomically thin carbon films, science. Science 306:666-669

6. Reina A, Jia X, Ho J, Nezich D, Son H, Bulovic V, Dresselhaus M, Kong J (2009) Large area, few-layer graphene films on arbitrary substrates by chemical vapor deposition. Nano Lett 9:30-35

7. Bonaccorso F, Lombardo A, Hasan T, Sun Z, Colombo L, Ferrari AC (2012) Production and processing of graphene and $2 d$ crystals Graphene is at the center of an ever growing research effort due to its unique to these crystals, accelerating their journey towards applications. Mater Today 15:564-589

8. Liu W, Jackson BL, Zhu J, Miao C, Park Y, Sun K, Woo J, Xie Y (2010) Large scale pattern graphene electrode for high performance in transparent. ACS Nano 4:3927-3932

9. Sun Z, Yan Z, Yao J, Beitler E, Zhu Y, Tour JM (2010) Growth of graphene from solid carbon sources. Nature 468:549-552 
10. Hirano R, Matsubara K, Kalita G, Hayashi Y, Tanemura M (2012) Synthesis of transfer-free graphene on an insulating substrate using a solid phase reaction. Nanoscale 4:7791-7796

11. Ayhan ME, Kalita G, Papon R, Hirano R, Tanemura M (2014) Synthesis of transfer-free graphene by solid phase reaction process in presence of a carbon diffusion barrier. Mater Lett 129:76-79

12. Vishwakarma R, Rosmi MS, Takahashi K, Wakamatsu Y, Yaakob Y, Araby MI, Kalita G, Kitazawa M, Tanemura M (2017) Transfer free graphene growth on $\mathrm{SiO}_{2}$ substrate at $250^{\circ} \mathrm{C}$. Sci Rep 7:43756

13. Araby MI, Rosmi MS, Vishwakarma R, Sharma S, Wakamatsu Y, Takahashi K, Kalita G, Kitazawa M, Tanemura M (2017) Graphene formation at $150{ }^{\circ} \mathrm{C}$ using indium as catalyst. RSC Adv 7:47353-47356

14. Elhamid A, Abd M, Hafez MA (2017) Room temperature graphene growth on complex metal matrix by PLD. Diam Relat Mater 80:162-167

15. Nakajima Y, Murata H, Saitoh N, Yoshizawa N, Suemasu T, Toko $\mathrm{K}$ (2019) Low-temperature $\left(400^{\circ} \mathrm{C}\right)$ synthesis of multilayer graphene by metal-assisted sputtering deposition. ACS Omega 4:6677-6680

16. Asaka K, Saito Y (2016) Spontaneous graphenization of amorphous carbon on clean surfaces of nanometer-sized nickel particles at room temperature. Carbon 103:352-355

17. Elnobi S, Sharma S, Araby MI, Paudel B, Kalita G, Yusop MZM, Ayhand ME, Tanemura M (2020) Room-temperature graphitization in a solid-phase reaction. RSC Adv 10:914-922

18. Dahal A, Batzill M (2014) Graphene - nickel interfaces : a review. Nanoscale 6:2548-2562

19. Kim E, An H, Jang H, Cho W-J, Lee N, Lee W-G, Jung J (2011) Growth of few-layer graphene on a thin cobalt film on a Si/SiO substrate. Chem Vap Depos 17:9-14

20. Amato $G$ (2018) High temperature growth of graphene from cobalt volume: Effect on structural properties. Materials 11:257

21. Macháč $P$, Hejna PO, Slepička $P$ (2017) Graphene growth by transfer-free chemical vapour deposition on a cobalt layer. $J$ Electr Eng 68:79-82
22. Majewska J, Michalkiewicz B (2013) Low temperature one-step synthesis of cobalt nanowires encapsulated in carbon. Appl Phys A 111:1013-1016

23. Zhang C, Zhu X, Wang Z, Sun P, Ren Y, Zhu J, Zhu J, Xiao D (2014) Facile synthesis and strongly microstructure-dependent electrochemical properties of graphene/manganese dioxide composites for supercapacitors. Nanoscale Res Lett 9:490

24. Gupta B, Kumar N, Panda K, Kanan V, Joshi S, Fisher IV (2017) Role of oxygen functional groups in reduced graphene oxide for lubrication. Sci Rep 7:45030

25. Yan J, Fan Z, Wei T, Qian W, Zhang M, Wei F (2010) Fast and reversible surface redox reaction of graphene- $\mathrm{MnO}_{2}$ composites as supercapacitor electrodes. Carbon 48:3825-3833

26. Cuesta A, Dhamelincourt P, Laureyns J, Alonso AM, Tascon JMD (1994) Raman microprobe studies on carbon materials. Carbon 32:1523-1532

27. Thambiliyagodage CJ, Ulrich S, Araujo PT, Bakker MG (2018) Catalytic graphitization in nanocast carbon monoliths by iron, cobalt and nickel nanoparticles. Carbon 134:452-463

28. Park J, Mitchel WC, Elhamri S, Grazulis L, Hoelscher J, Mahalingam K, Hwang C, Mo SK, Lee J (2015) Observation of the intrinsic bandgap behaviour in as-grown epitaxial twisted graphene. Nat Commun 6:5677

29. Lu L, Hosson JD, Pei Y (2018) Low-temperature synthesis of large-area graphene-based carbon films on Ni Mater. Des 144:245-255

30. Sutter EA, Sutter PW (2011) Giant carbon solubility in Au nanoparticles. J Mater Sci 46:7090-7097

31. Mclellan RB (1969) The solubility of carbon in solid gold, copper, and silver. Scr Met 3:389-391

Publisher's Note Springer Nature remains neutral with regard to jurisdictional claims in published maps and institutional affiliations. 